\title{
Analysis of the paleomagnetism and rock magnetism of the Surco intrusion, Peru: an attempt to obtain a southern hemisphere reversal record
}

\author{
R.J. Weeks, J.R. Dunn and M. Fuller \\ Dept. Geological Sciences, University of California, Santa Barbara, CA 93106 (U.S.A.) \\ L. Quispesivana \\ Instituto Geologico y Metalurgico, Lima (Peru)
}

(Accepted for publication March 1, 1990)

\begin{abstract}
Weeks, R.J., Dunn, J.R., Fuller, M. and Quispesivana, L., 1990. Analysis of the paleomagnetism and rock magnetism of the Surco intrusion, Peru: an attempt to obtain a southern hemisphere reversal record. Phys. Earth Planet. Inter., 64: 176-186.

Investigation of the Surco pluton, a granodioritic body approximately $12 \mathrm{~km}$ in diameter and age $20 \mathrm{Ma}$, located near Lima, Peru, was initiated in order to obtain a geomagnetic reversal record. More than 300 samples provide a complete section through the intrusion. Preliminary results obtained using conventional paleomagnetic techniques indicate that the western part of the pluton records the ambient field behavior well; a consistent reversed direction is followed by a partial reversed to normal transition as one progresses into the core of the intrusion. Plots of NRM vs. IRM(S) demagnetization indicate a steady decrease in the geomagnetic field intensity prior to the reversal. The intrusion does not appear to have recorded the recovery of the normal intensity after the reversal.

The existence of a complete section through the intrusion permitted, in principle, the observation of a symmetrical record of the reversal from each side of the pluton. However, the results from the eastern Surco section present a confusing picture and reveal significant variations in rock magnetic and remanence properties along section. Magnetic properties of mineral separates were studied in an attempt to understand variability in the rock as a paleomagnetic recorder. In general, the feldspars contain an unstable magnetization, while the mafic minerals hold a more stable magentization. In the eastern Surco, there are considerable variations in their magnetic properties.
\end{abstract}

\section{Introduction}

Detailed geomagnetic reversal records have now been obtained from sediments, lavas and plutonic rocks. Qualitatively the records from sediments and intrusions have in common a continuous, but typically low pass frequency recording process, while those from lavas provide spot readings, in time, of the geomagnetic field.

A number of reversal records from shallow granodioritic plutons have been reported (Dodson et al., 1978; Williams and Fuller, 1982), the most convincing being the reversed to normal record obtained from the Miocene Tatoosh intrusion in central Washington State. The VGP path was constrained in longitude and appeared to show details of behavior such as a looping of the VGP back to equatorial latitudes from the normal post-reversal location. Detailed rock magnetism and microanalysis (Wu et al., 1974) of the remanence properties showed that the 'primary' magnetization was carried by fine magnetite contained within plagioclase feldspar crystals. This magnetization had an extremely narrow, high laboratory 
blocking temperature range between $550^{\circ}$ and $560^{\circ} \mathrm{C}$. Records have also been obtained from two other granodioritic intrusions: the Agno intrusion in the Philippines (Williams and Fuller, 1983), and the Laurel Hill intrusion in Oregon (Dodson et al., 1978).

Reversal records have been reviewed on numerous occasions (Fuller et al., 1979; Laj et al., 1990) and the data have been used to provide evidence that transitional fields were dominantly zonal (Hoffman, 1977; Hoffman and Fuller, 1978). A number of forward models of transitional fields were developed (Hoffman, 1978; Williams and Fuller, 1981) and it quickly became clear that data from the southern hemisphere and from equatorial regions were needed to constrain these models and hence the zonal harmonic content of the transitional fields. This resulted in an exploration, by the research group at Santa Barbara, of sites in Peru, and the eventual choice of the Surco intrusion at latitiude $11^{\circ} \mathrm{S}$ for detailed study. In this paper we describe paleomagnetic results from the Surco intrusion, which display what appears to be a partial record of a reversed to normal reversal. In addition, we discuss the magnetic properties in an attempt to interpret the variability of the intrusion as a paleomagnetic recorder.

\section{Geology}

The Surco intrusion is a small pluton consisting mainly of a coarse-grained granodiorite. It is part of a belt of Tertiary stocks, plutons and batholiths which lie slightly to the east of the main coastal batholith in Peru (Pitcher and Cobbing, 1985) (Fig. 1). They form a more or less continuous outcrop of scattered stocks and batholiths stretching south over $1000 \mathrm{~km}$ from the Equador border and spreading inland up to $200 \mathrm{~km}$ from the Peruvian coast. Not much is known about these rocks, but dating (Wilson, 1975) has shown that they must represent a second phase of intrusive and extrusive volcanism occurring after the mostly Cretaceous emplacement of the coastal batholith. The origin of the magma is thought to have been related to subduction, but it must have acquired a

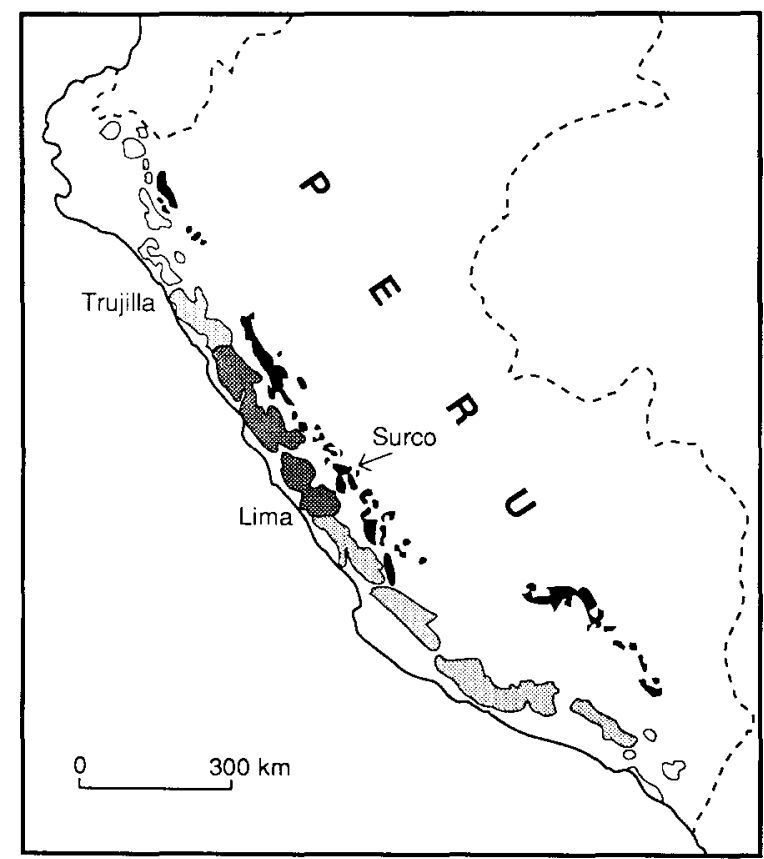

Fig. 1. Location and setting of the Surco pluton.

considerable crustal component upon rising through what was by Tertiary time, a thick and well-developed continental crust.

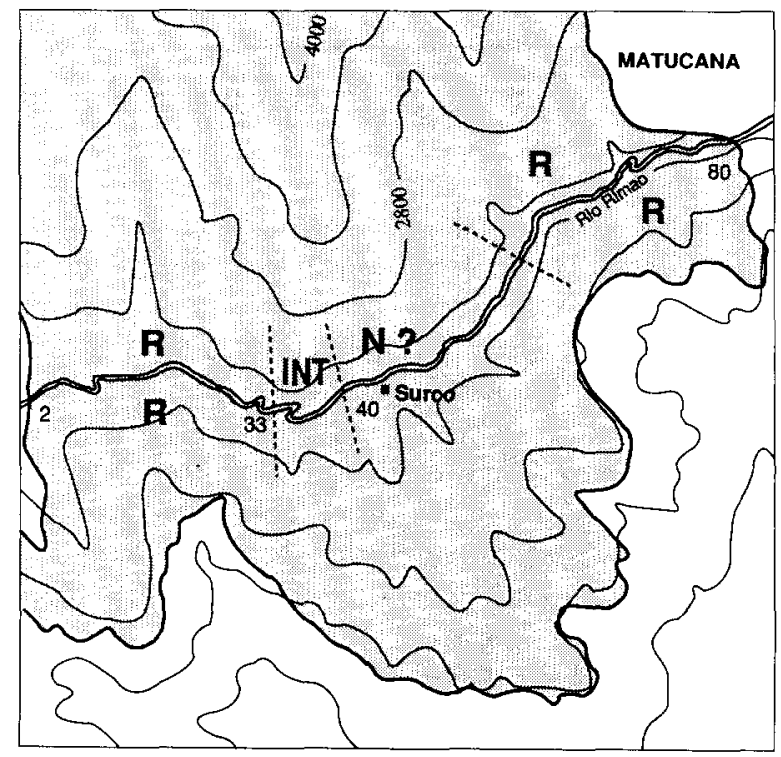

Fig. 2. Sampling section through the Surco pluton. Approximate locations of normal, reversed and intermediate polarity zones are indicated. 


\section{Sampling}

Standard paleomagnetic sampling techniques were used to obtain more than 300 cores from nearly 80 sites (Fig. 2). The sampling comprises a complete section through the intrusion along the Rio Rimao valley. In the eastern half of the pluton we were fortunate enough to have continuous fresh outcrop resulting from the recent construction of a new section of the main highway. It should be noted that the site numbers are geographically sequential going from site 1 in the extreme western part of the pluton through to site 80 in the east. Throughout most of the pluton, sites are separated by several hundred meters, but field trips in 1982 and 1984 established the location of a possible reversed to normal polarity transition between sites 33 and 40 (near the center of the intrusion), and sampling has been dense in this region with sites separated by a few meters only.

\section{Demagnetization}

\subsection{Alternating field demagnetization}

In general alternating field (AF) techniques were unsuccessful in removing present field overprint magnetizations and isolating earlier magnetizations in this intrusion. Typical demagnetization results are shown in Fig. 3.

Curves of magnetization $(J)$, normalized to the $\operatorname{NRM}\left(J_{0}\right)$, as a function of demagnetization level show that a soft magnetization is being removed and the directional plots indicate that this appears to be the present field direction. Only partial removal of the normal overprint is achieved, and samples either show no indication of a second magnetization vector, or random directions related to noise acquired in the demagnetization process. Attempts to obtain paleomagnetic information from other plutonic rocks such as the Tatoosh and Agno intrusions illustrate that the poor response to AF cleaning may be common in acid to intermediate intrusive rocks. The abundance of large multidomain magnetite means that the higher coercivity components of magnetization, often carried by fine-grained magnetite inclusions within
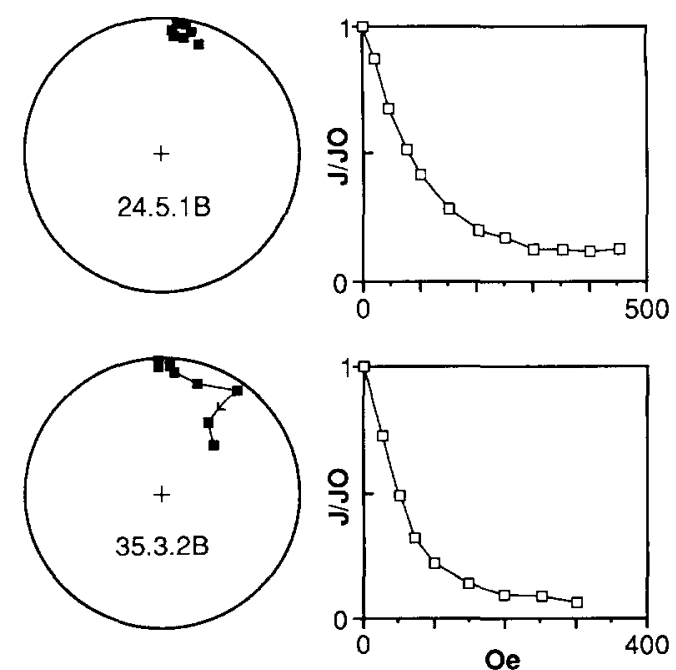

Fig. 3. Example AF demagnetizations (lower hemisphere equal area projections and $J / J_{0}$ plots of magnetization intensity).

other minerals, are small compared with the NRM and that the rock is susceptible to ARM acquisition during demagnetization. Median destructive fields are between 8 and $10 \mathrm{mT}$. Beyond values of $30-40 \mathrm{mT}$ there is no further demagnetization and directions show random directions characteristic of ARM noise derived from the AF demagnetization procedure.

\subsection{Stepwise thermal demagnetization}

A number of samples throughout the pluton were analyzed using conventional stepwise thermal demagnetization. There is a considerable variety in demagnetization behavior sometimes even between adjacent samples at the same site and often between samples from different sites well separated along the section. Differences in $J / J_{0}$ curves seem to indicate significant changes in remanence properties which are not always suggested or paralleled by observations of other physical properties such as those seen in examination of thin sections, or in conventional rock magnetic measures. There appear to be three fairly distinct kinds of behavior and examples of these are shown in Fig. 4.

Figure 4(a) shows results from a sample with a single component of magnetization unblocked at 


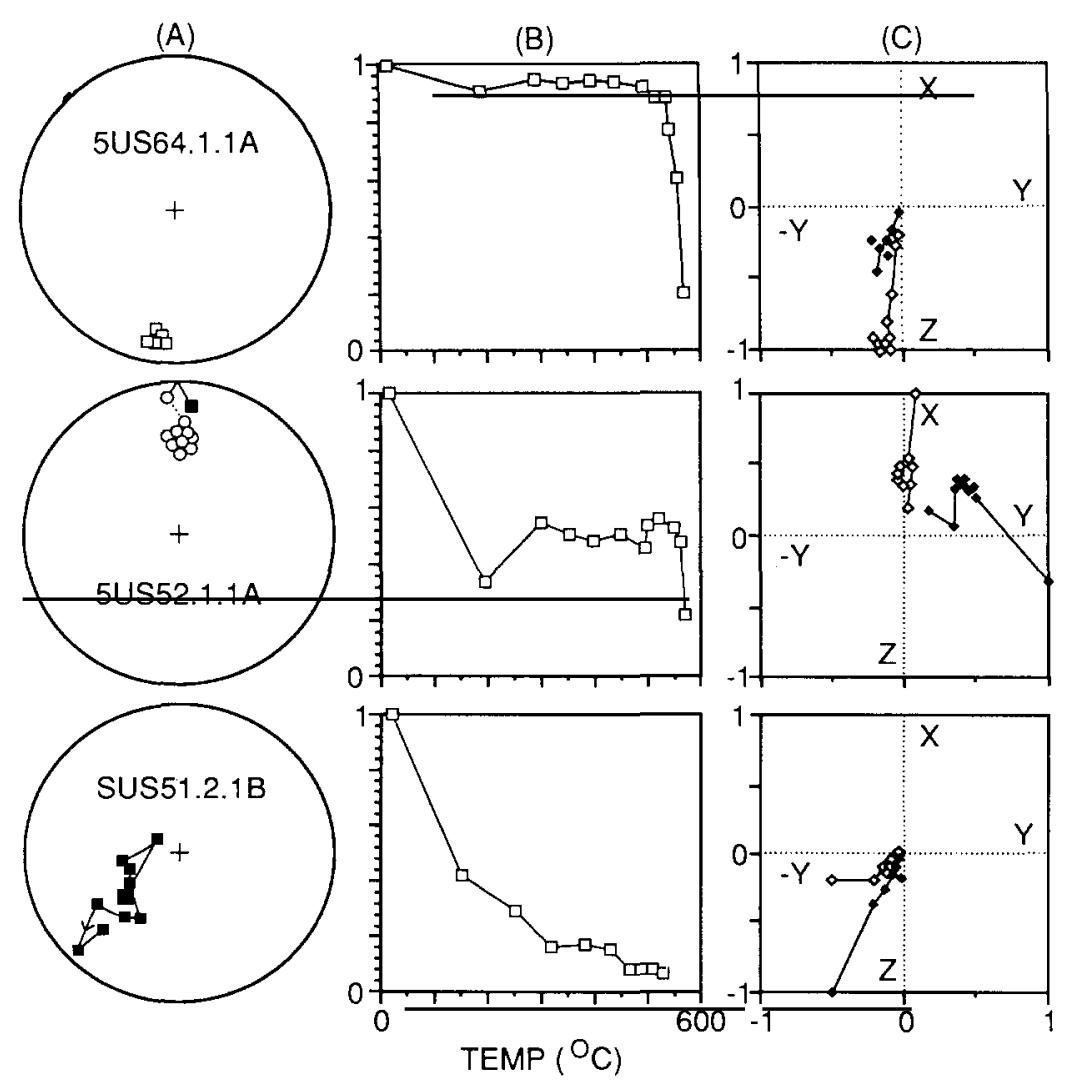

Fig. 4. Example stepwise thermal demagnetizations. (A) Equal area projections; (B) $J / J_{0}$ curves; (C) Zijderveld orthogonal plots (open symbols $X$ vs. $Y$ in geographic coordinates, solid symbols $Z$ vs. $X$ or $Y$ ).

high temperature. Magnetization remains constant until a temperature of $530^{\circ} \mathrm{C}$ is reached. Samples exhibiting this kind of behavior often do have different rock magnetic properties and tend to appear darker. This change in color is produced by a darker grey shade in the felsic minerals rather than by an increase in the proportion of dark mafic minerals.

Figure 4(b) illustrates the removal of a lowtemperature component often followed by a recovery of intensity, implying the presence of an opposed component, and finally removal of a small high unblocking temperature vector which is blocked within a narrow range of temperatures between $530-560^{\circ} \mathrm{C}$. This is manifested in the rapid decrease at the end of the $J / J_{0}$ plot and it is generally in this section of the demagnetization that the magnetization of these samples reaches a stable end-point on the directional plot and shows a straight line to the origin on a Zijderveld plot. Figure 4(c) shows the removal of a large low-temperature component with little evidence of a hightemperature component. Most of the NRM is removed by $400^{\circ} \mathrm{C}$ and the directions either continuously move along a particular track, reaching no stable end-point, or show noisy demagnetizations with fairly random changes in direction between demagnetization steps. Standard rock magnetic analyses (IRM acquisition and demagnetization, $\mathrm{Hrc}, \mathrm{Hc}$ ) reveal no distinction between samples of type (b) and (c).

\subsection{Continuous thermal demagnetization}

This technique involves essentially continuous measurement at high temperature (Dunn and Fuller, 1984) and promises to be the most succesful approach to demagnetization for these and 

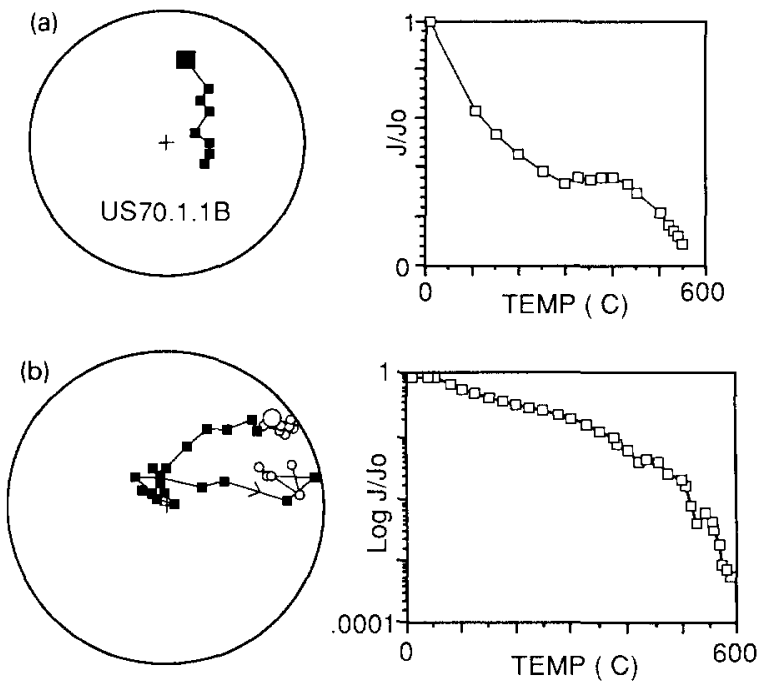

Fig. 5. Example continuous thermal demagnetizations. (a) Lower hemisphere equal area projections; (b) $J / J_{0}$ plots.

other plutonic rocks such as the Tatoosh pluton. The principle advantage of measurement at high temperature is that the danger of acquisition of spurious magnetizations upon cooling, whether from small ambient fields or from interactions within the sample, is eliminated. It is the principle procedure used in this study and typical results are illustrated in Fig. 5.

Another advantage is that an exceptionally detailed picture of the thermal demagnetization is obtained and often allows resolution of up to three distinct vectors present in a sample at different blocking temperatures (Fig. 5b). In fact, the detail is so much greater than that provided by stepwise thermal demagnetization that types of behaviour are displayed which have not been seen before and which seem to require new interpretions. In particular, demagnetization of components antipodal to the characteristic magnetization is frequently seen suggesting the importance of shielding. A number of cores were split, one half being demangnetized by the stepwise, and the other by the continuous, thermal approach. In many cases the results are broadly similar while in others they are quite different. It is felt that these differences do not result entirely from differences inherent in the two techniques used, but that they are mostly consistent with an emerging picture of the magnetization of these kinds of coarse-grained plutonic rocks in which the remanence is inhomogeneous and can vary on all distance scales. This conclusion is supported by the observation that adjacent samples can occasionally exhibit quite different behavior when demagnetized using the same demagnetization technique.

\section{Rock magnetism}

The dominant contribution to the magnetism of a silicic intrusive rock is commonly from large $\mathrm{Fe}-\mathrm{Ti}$ oxide grains, usually Ti-poor titanomagnetites which are either primary magmatic minerals or alteration products of mafic minerals. These grains are multidomain and can carry a relatively large, but soft, secondary component of magnetization. Previous analyses of plutonic rocks (Evans et al., 1968; Hargraves and Young, 1969; Evans and Wayman, 1970; Murthy et al., 1971; Wu et al., 1974; Evans, 1977; Davis, 1981; Scofield and Roggenthen, 1986) have shown that stable, possibly primary, magnetization can reside in single domain and pseudo-single domain $\mathrm{Fe}-\mathrm{Ti}$ oxides contained within either plagioclase feldspar crystals or pyroxenes. These oxides could form either as primary inclusions, by exsolution from the host mineral, or by a hydrothermal alteration reaction. The first two processes will probably result in a primary TRM because it is likely that the mineral is produced at temperatures above the Curie temperature, while the third process may produce either a TCRM or a CRM depending on the temperature at which the reaction takes place.

In order to obtain a reliable record of the geomagnetic field from a coarse-grained silicic pluton, the magnetization of the fine oxide particles is indeed a TRM and there must be a sufficient amount of them of preserve a measurable signal after the soft multidomain components of magnetization have been demagnetized. In the Tatoosh granodiorite intrusion (Wu et al., 1974) it became clear that the stable magnetization was carried by 'inclusions' within the plagioclase feldspars. Since the Tatoosh has produced the most successful reversal record yet obtained from a plutonic rock, it seems appropriate to use it as a 


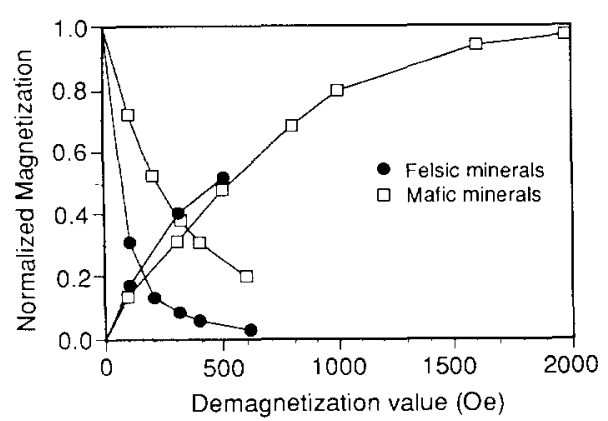

Fig. 6. IRM acquisition and demagnetizations plots comparing results for the dark, mafic phases with those for the felsic minerals.

standard for comparison when examining the rock magnetism of similar intermediate to acidic plutons.

Magnetic separates from the Surco granodiorite were made from various sites. By varying the field used in the separation, it was possible to separate the felsic minerals (mostly plagioclase and quartz) from the dark mafic minerals (biotite and hornblende). Synthetic samples of the separated fractions were made by dispersing the grains in potassium bromide which was then compressed into pellets. The Isothermal Remanent Magnetization (IRM) acquisition and demagnetization characteristics of separates obtained from samples collected between sites 30 and 40 are shown in Fig. 6. These results are typical for all sites within this western region of the pluton (sites 2-45). The magnetization of the light mineral fraction is, as expected, weak, but is unexpectedly quite soft with a remanence coercivity $(\mathrm{Hrc})$ of about $15 \mathrm{mT}$. Biotites and hornblendes often contain significant amounts of large, multidomain magnetite and indeed the magnetization of these minerals in the Surco rocks is much stronger. Moreover, this magnetization is quite hard and has a $\mathrm{Hrc}$ of about $34 \mathrm{mT}$. So, the distribution of magnetic characteristics produced by magnetic grains contained within various mineral phases is apparently contrary to that seen in the Tatoosh intrusion. At other locations in the Surco (sites 62-65) we find that the feldspars, in this case picked out by hand, carry a harder magnetization (in terms in $\mathrm{Hrc}$ ) similar to that seen in feldspars from the Tatoosh (Fig. 7). So it appears that the magnetic characteristics of the mineral fractions are homogeneous throughout large regions of the intrusion, but vary considerably between these regions. The transition zones between these zones appear to be quite sharply defined.

The remanence properties of samples from the various regions of the pluton were then examined using comparisons of the AF demagnetization of NRM with demagnetization of IRM(S) (Fuller et al., 1988). They showed that plots of NRM vs. IRM demagnetization could be useful in distinguishing between primary TRM and other kinds of magnetization. In these diagrams the ratio of NRM to IRM is compared at increasing AF demagnetization levels: the slope of the curve provides information on the relative stability of the NRM compared to the stability of the IRM, while the ratio indicates the relative efficiency of the NRM acquisition process. The ratio of NRM to IRM(S) at various demagnetization levels has also been used as a measure of relative paleointensity in lunar and terrestrial rocks (Cisowski and Fuller, 1986). They showed that this ratio documents the decay in field intensity that occurred during reversals recorded in the Tatoosh and Agno intrusions. The western region of the Surco intrusion is of particular interest because it possibly contains a record of an $\mathrm{R}-\mathrm{N}$ geomagnetic reversal and we have thus concentrated analysis on this region (sites 6-50). Going eastward into the pluton a reversed direction is recorded from sites 6-33 after which there is a section of transitional directions (sites 34-39) before a normal direction is reached at site 40 . The AF demagnetization of

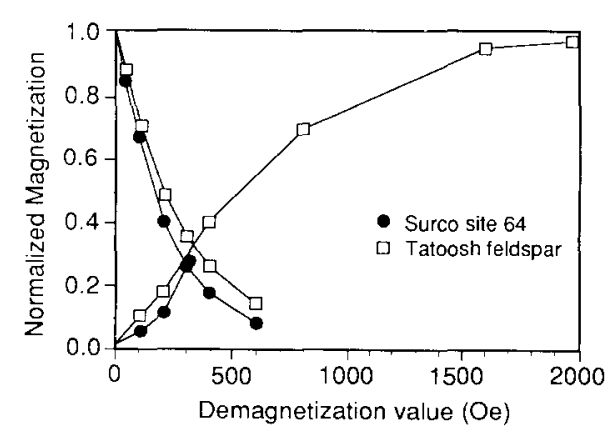

Fig. 7. Comparison IRM acquisition and demagnetization of Tatoosh feldspars and feldspars from site 64 in the Surco. 


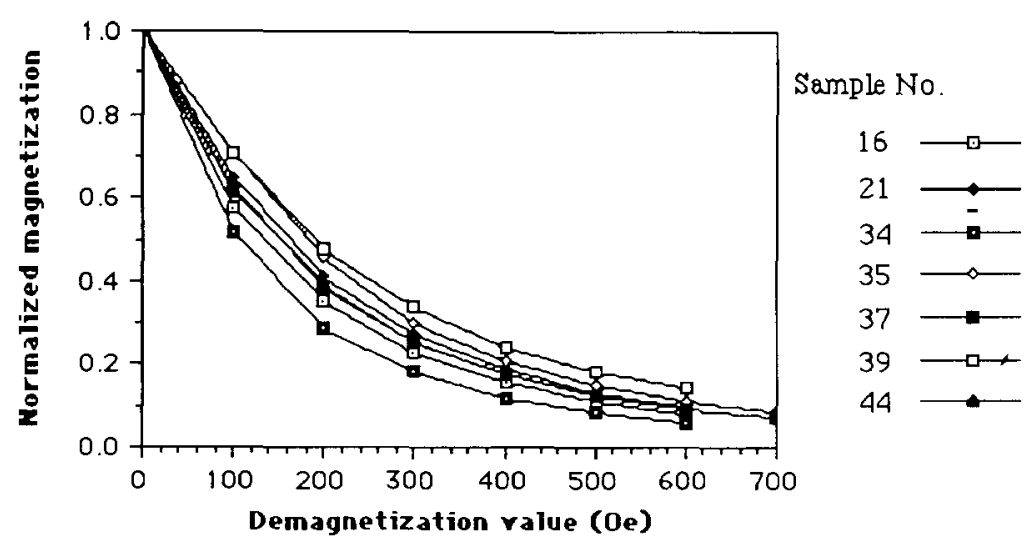

Fig. 8. Normalized IRM(S) demagnetizations of samples from Surco sites 16-44.

$\operatorname{IRM}(\mathrm{S})$ for samples between site 16 and 44 are shown in Fig. 8.

The samples all show very similar curves and display fairly soft IRM(S) with median destructive fields of between 10 and $20 \mathrm{mT}$. In Fig. 9 the AF demagnetization of NRM is plotted against that of IRM(S) for the same samples.

These plots reveal an along section change in the NRM characteristics of the samples relative to their IRM(S) values. Results for sites between 34 and 44 form a group of concave curves at low ratios (NRM/IRM) of about $10^{-3}$ while sites 21 and 16 have fairly linear curves at higher ratios. This difference in curve shape results from the

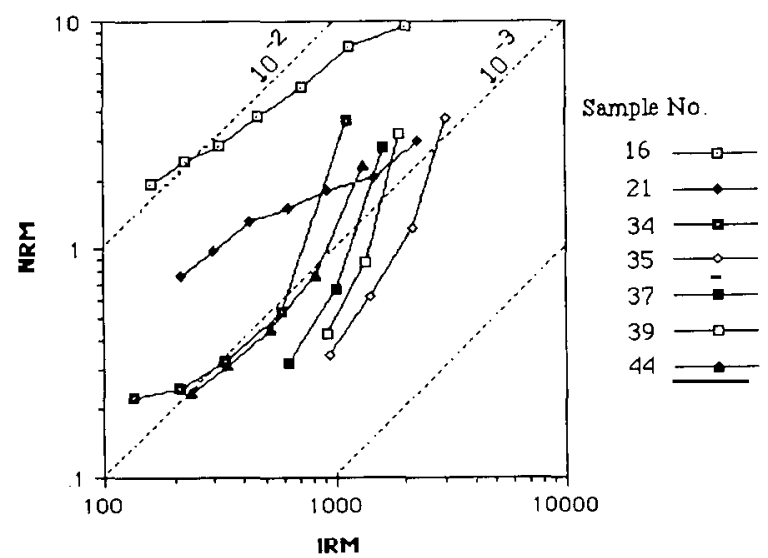

Fig. 9. Demagnetization of NRM vs. demagnetization of IRM(S) for sample locations from site 16 westward to site 44. Dotted lines represent lines of constant NRM/IRM (ratios are indicated). higher slope for sites 34-44 at low demagnetization values of NRM, which corresponds to the removal of a soft normal overprint. This overprint is apparently not present in sites 16 and 21 to the west. At higher demagnetization values the slopes of all the samples approach the same value of about 1. However, the ratios (NRM/IRM) are still dispersed. In fact there is a progressive west to east decrease in this ratio at these higher demagnetization values: site 16 has a value of about $10^{-2}$, site 21 about $5 \times 10^{-3}$ and sites $33-44$ are about $10^{-3}$ or just below. The data shown in Fig. 8 suggest that this variation is not all produced by variation in IRM(S), and hence it must be, at least partially, caused by changes in NRM which are not tied to magnetic mineral content or other characteristics which control the IRM signal. If we regard the NRM/IRM(S) ratio as a measure of relative paleointensity (Cisowski and Fuller, 1986) then such a change is consistent with the recording of a progressively weaker geomagnetic field by sites further eastward into the intrusion. In fact this variation is very similar in magnitude to that seen in the Tatoosh and Agno intrusions (Cisowski and Fuller, 1986).

\section{Directional results}

The following summary of results from the Surco consists mostly of results obtained using continuous thermal demagnetization. For convenience these results are divided, using a change in 
the remanence properties which occurs near the center of the intrusion, into those from the western part of the pluton (sites 2-42) and those from the eastern part (sites 43-70).

\subsection{Western Surco (sites 2-33)}

Figure 10 illustrates some typical results from this section of the pluton. A clockwise rotated, steep (inclination $30-50^{\circ}$ ), reversed direction is in general isolated between about $400^{\circ}$ and $550^{\circ} \mathrm{C}$ after removal of a lower temperature present field overprint. The declinations appear to document the post-early Miocene clockwise rotation observed in this part of Peru (Heki et al., 1984). A change in the character of the demagnetization is noted with distance into the pluton. There tends to be a normal overprint in the more easterly sites which is not present at the westernmost sites and the $J / J_{0}$ plots show a significant high-temperature component in the west becoming less pronounced eastward.

This eastward decrease in intensity of the hightemperature component is consistent with the decrease in $\mathrm{NRM} / \mathrm{IRM}(\mathrm{S})$ ratio and lends some support to the conclusion that these changes represent the decay in intensity of the geomagnetic field prior to a reversal of the geomagnetic field. However, an alternative explanation might feature a change in remanence characteristics of the rock with distance into the pluton due, for example, to viscous decay; rocks further into the intrusion being held at elevated temperatures for longer time periods. This would also be consistent with the increasing presence of a normal overprint.
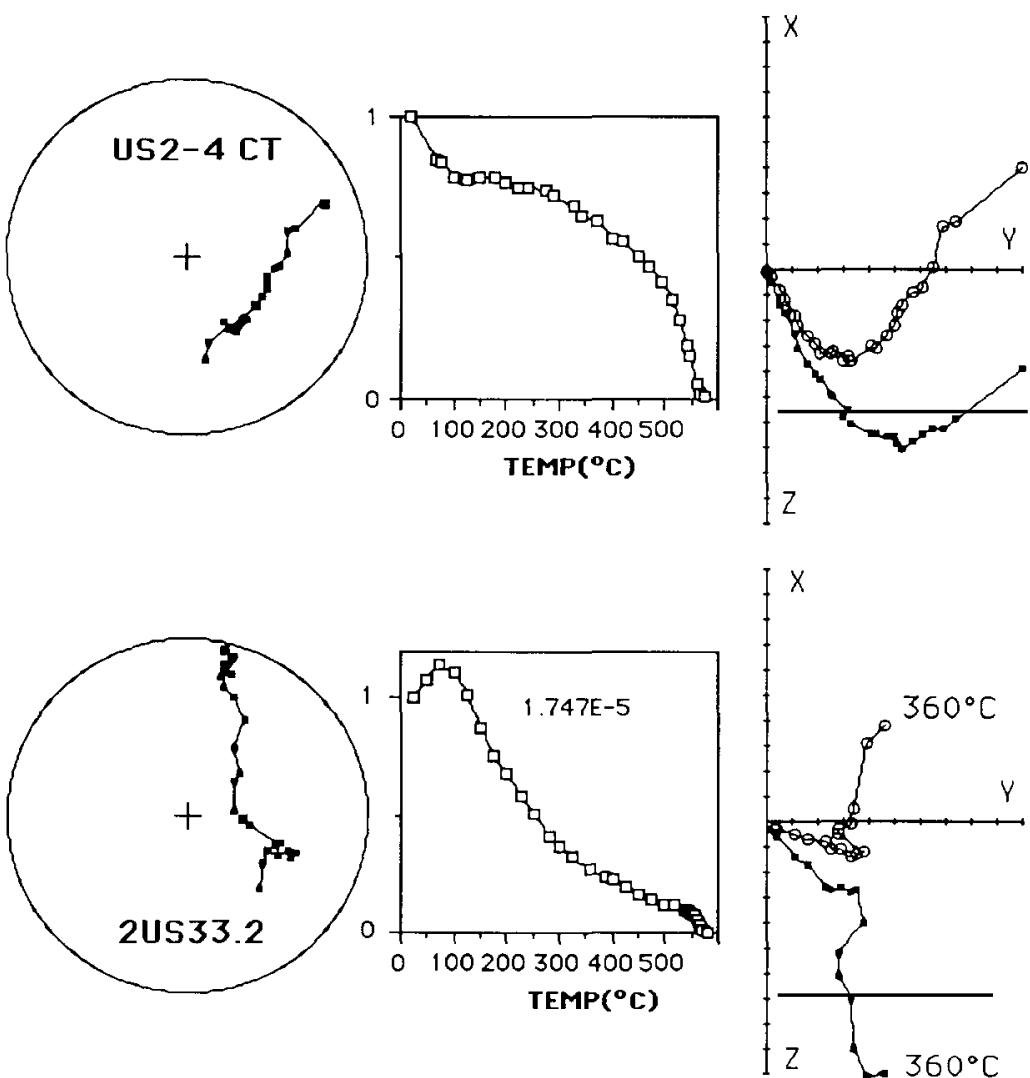

Fig. 10. Examples of continuous thermal demagnetizations showing the clockwise rotated reversed direction seen in the western Surco from sites 2-33. 


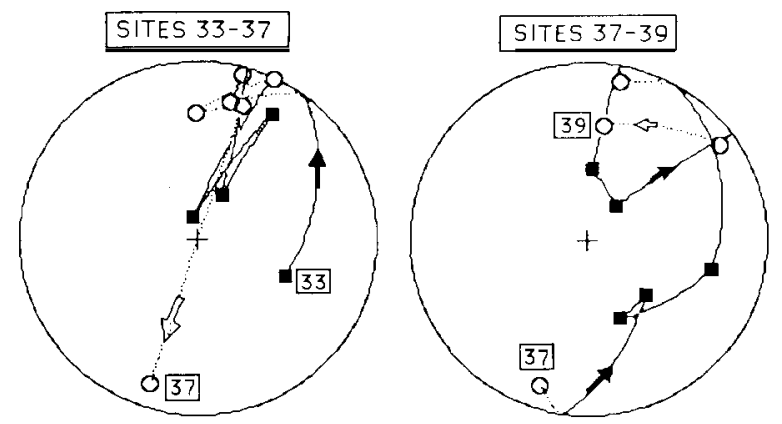

Fig. 11. The sequence of directions between sites 33 and 39 (lower hemisphere equal area plots).

\subsection{Western Surco (sites 34-42)}

Early work on the Surco showed that a number of samples located between sites 39 and 42 had predominantly normal directions and that some sites between 34 and 39 gave intermediate results. The immediate inference was that a reversal should have occurred between the last reversed site (site 33) and site 39. However, a number of factors make this conclusion uncertain. First, the normal direction should show the same (post-early Miocene) rotation that is seen in the reversed samples. It is, however, unrotated suggesting the possibility of a more recent overprint rather than the conclusion of the reversal. Secondly, although some samples gave stable intermediate results, many had demagnetization behavior which, due to the presence of noise and/or continuous directional tracking, did not display stable end-point directions. In addition, the normal samples do not show the expected recovery in intensity of magnetization and have low NRM/IRM(S) ratios indicating either that the reversal record is incomplete and the full normal polarity is never seen, or again that the remanence has been subjected to thermoviscous or hydrothermal alteration. A summary of the sequence of directional results (going from west to east) obtained from those samples which showed stable high-temperature magnetizations together with straight line to the origin Zijderveld plots is given in Fig. 11. These directions are picked from the straight line to the origin segments of the Zijderveld plots.

\subsection{Eastern Surco (sites 42-70)}

It was originally hoped that a second, "mirror image' record of the reversal would be obtained from this half of the pluton. Results from this region are summarized in Fig. 12. The pattern of directional behavior does not fit into this simple interpretation and there are visible variations in the rock type along section. The reversed direction, observed in the western part of the pluton (sites 2-33), is not found until the very eastern

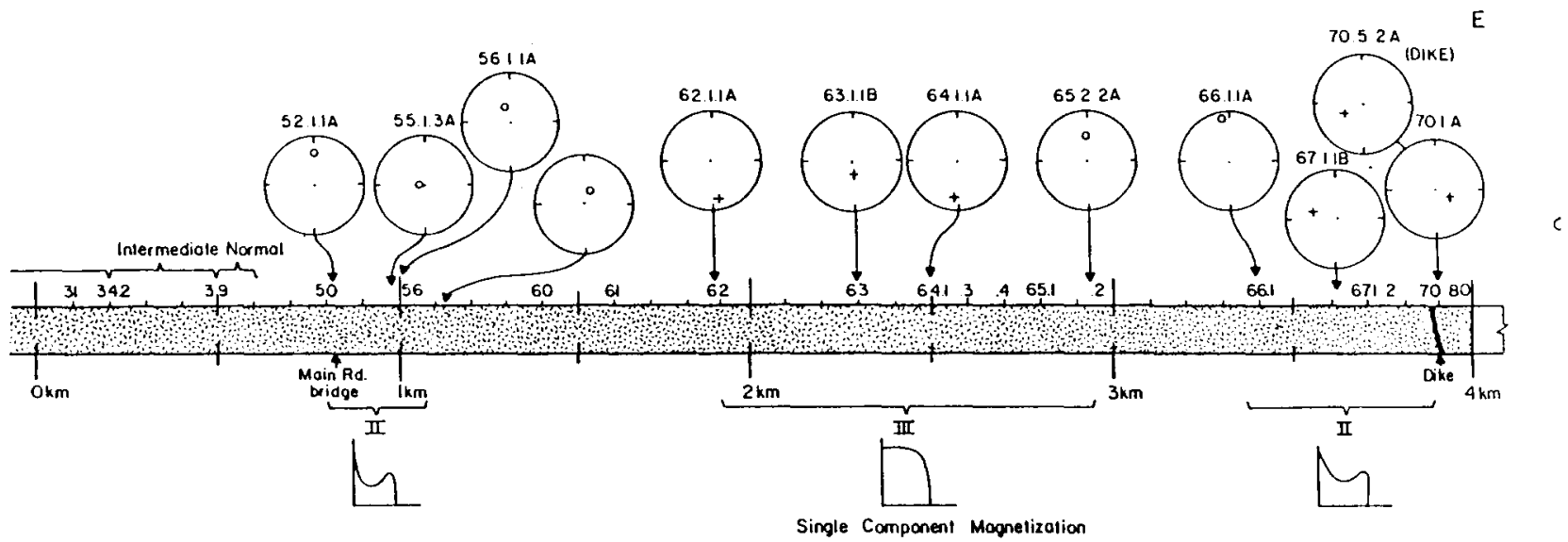

Fig. 12. Summary of the paleomagnetic results from the eastern part of the Surco intrusion. Site numbers are indicated and, where good results were obtained, the field direction obtained from a sample at the site is shown. Representative $J / J_{0}$ plots for the various regions of the eastern intrusion are displayed. 
edge of the intrusion is reached (sites 70-80). Between sites 42 and 70 the magnetic characteristics vary and there are a number of apparent switches in polarity.

\section{Discussion}

Rock magnetic and paleomagnetic data and simple inspection of thin sections all suggest that the western section of the Surco intrusion can be regarded as fairly homogeneous in rock type and in magnetic recording characteristics. However, the eastern part of the pluton has visible variations in rock type, a greater amount of faulting and mineralization, and variations in rock magnetic and paleomagnetic properties. Any hope of obtaining a reliable reversal record from an intrusion is based on finding a sufficiently large region with homogeneous recording characteristics. Such a region might be defined using rock magnetic characteristics and, as described above, the western region of the Surco pluton presents fairly homogeneous rock magnetic results. A reversed to normal transition is found in this region of the intrusion between sites 33 and 39 and this study has focused upon those results.

The results from the transition show a number of relevant features which bear upon their interpretation. First, the pre-transition reversed direction shows the clockwise tectonic rotation expected in this region for rocks of this age while normal direction following the reversal is unrotated, suggesting that, either only a partial reversal is recorded, or that this is a present field overprint. Intermediate directions do not lie on the great circle path between the reversed and normal directions, neither do they follow demagnetization tracks of the individual samples. This would seem to discount simple superposition of normal and reversed vectors as the explanation for the sequence of intermediate directions observed. The intensities of the high-temperature magnetization component and the NRM/IRM(S) ratio both decrease in the reversed rocks as the reversal region is approached and reach a minimum for the intermediate samples. However, the normal samples following the reversal do not show the ex-

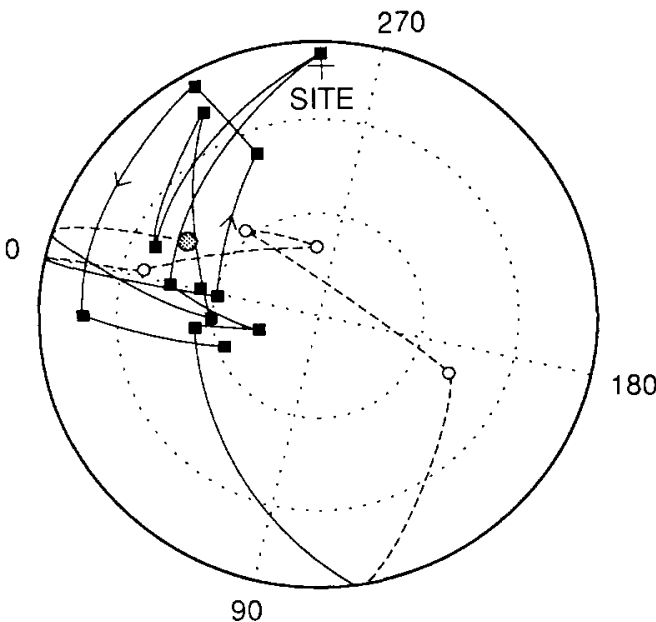

Fig. 13. VGP path for the partial reversal recorded in the western Surco viewed from above the North Pole (equal area upper hemisphere projection).

pected recovery in intensity or in NRM/IRM(S) ratio. These observations suggest that the sequence of directions observed in the western Surco represents either a partial reversal record or a complex magnetization history resulting from undetermined processes and events.

If the reversal record is a true one then it represents a predominantly near-sided path at the mean longitude lying about $60^{\circ}$ to the east of the site. The path defines a large loop from the rotated reversed location to a direction close to the normal and back to the initial reversed direction before proceeding finally to the normal direction (Fig. 13). There has been much discussion recently about the possibility that there are preferred intermediate directions of the geomagnetic field during transitions. This follows the observation of 'hangups' (near-stationary intermediate field directions) and 'rebounds' (directions which are returned to after departure to other directions) in directional records of transitions (Mankinen et al., 1985; Laj et al., 1987). The transition displayed in the Surco shows two directions which could be described as both hangup and rebound directions. These directions are the tectonically rotated reversed direction and a VGP location at about $65^{\circ} \mathrm{N}, 10^{\circ} \mathrm{E}$.

The paleomagnetic study of the Surco seems to support an observation also made for the Tatoosh 
intrusion that the NRM can vary on all scales from centimeters to kilometers. However, the rock magnetic and remanence studies suggest that large segments (on the order of kilometers) of the pluton have fairly constant properties which vary considerably between segments. The reason for the variability in NRM is unknown but may be connected with cooling processes for the pluton which in detail might be highly non-homogeneous.

\section{References}

Cisowski, S. and Fuller, M., 1986. Lunar paleointensities via the IRMs normalization method and the early magnetic history of the moon. In: W.K. Hartman, R.J. Phillips and G.J. Taylor, (Editors), Origin of the Moon, pp. 411-424.

Davis, K.E., 1981. Magnetite rods in plagioclase as the primary carrier of Stable NRM in ocean floor gabbros. Earth Planet. Sci. Lett., 55: 190-198.

Dodson, R., Dunn, J.R., Fuller, W., Williams, I., Ito, H., Schmidt, V.A. and Wu Yu, M., 1978. Paleomagnetic record of a late Tertiary field reversal. Geophys. J., 53: 373.

Dunn, J.R., and Fuller, M., 1984. Thermal demagnetization with measurements at high temperature using SQUID magnetometer. EOS (Trans. Am. Geophys. Union), 65: 863.

Evans, M.E., 1977. Single domain oxide particles as a source of thermoremanent magnetization. J. Geomag. Geoelectr., 29: $267-275$.

Evans, M.E., and Wayman, M.L., 1970. An investigation of small magnetic particles by means of electron microscopy. Earth Planet. Sci. Lett., 9: 365-370.

Evans, M.E., McElhinny, M.W. and Gifford, A.C., 1968. Single domain magnetite and high coercivities in a gabbroic intrusion. Earth Planet. Sci. Lett., 4: 142-146.

Fuller, M., Williams, I.S. and Hoffman, K.A., 1979. Paleomagnetic records of geomagnetic field reversals and the morphology of transitional fields. Rev. Geophys. Space Phys., 17: 179-203.

Fuller, M., Cisowski, S., Hart, M., Haston, R. and Schmidke, E., 1988. NRM : IRM(S) demagnetization plots: An aid to the interpretation of Natural Remanent Magnetization. Geophys. Res. Lett., 15: 518-521.

Hargraves, R.B. and Young, W.M., 1969. Source of stable remanent magnetism in Lambertville diabase. Am. J. Sci., 267: $1161-1177$.

Heki, K., Hamano, Y., Kinoshita, H., Taira, A. and Kono, M., 1984. Paleomagnetic study of Cretaceous rocks of Peru, South America: Evidence of rotation of the Andes. Tectonophysics, 108: 267-281.

Hoffman, K.A., 1977. Polarity transition records and the geomagnetic dynamo. Science, 196: 1329-1332.

Hoffman, K.A., 1978. Transitional field configurations and geomagnetic reversal. Nature, 273: 715-718.

Hoffman, K.A. and Fuller, M., 1978. Transitional field configurations and geomagnetic reversal. Nature, 273: 715-718.

Laj, C., Guitton, S. and Kissel, C., 1987. Rapid changes and near stationarity of the geomagnetic field during a polarity reversal. Nature, 330: 145-148.

Laj, C., Weeks, R.J. and Fuller, M., 1990. Observations and models of reversal transition fields, NATO meeting/NATO ASI series volume: Paleomagnetism and Geomagnetism, pp. $185-203$.

Mankinen, E.A., Prevot, M., Gromme, C.S. and Coe, R.S., 1985. The Steen's Mountain geomagnetic polarity transition, 1, Directional history, duration of episodes and rock magnetism. J. Geophys. Res., 90: 10 379-10 417.

Murthy, G.S., Evans, M.E. and Gough, D.I., 1971. Evidence of single-domain magnetite in the Michikamau anorthosite. Can. J. Earth Sci., 8: 361-370.

Pitcher, W.S. and Cobbing, E.J., 1985. Phanerozoic plutonism in the Peruvian Andes. In: W.S. Pitcher, M.P. Atherton, E.J. Cobbing and R.D. Beckinsale. (Editors), Magmetism at a Plate Edge. Halsted Press, New York, pp. 19-25.

Scofield, N. and Roggenthen, W.M., 1986. Prelogic evolution of plagioclase-rich cumulates from the Wichita Mountains, Oklahoma: Effects upon magnetic remanence properties. Geology, 14: 908-911.

Williams, I.S. and Fuller, M., 1981. Zonal harmonic models of reversal transition fields. J. Geophys. Res., 86: 1165711665.

Williams, I.S. and Fuller, M., 1982. A miocene polarity transition ( $\mathrm{R}-\mathrm{N}$ ) from the Agno batholith, Luzon. J. Geophys. Res., 87 (B11): $9408-9418$.

Wilson, P.A., 1975. K-Ar age studies in Peru with special reference to the emplacement of the Coastal Batholith. Ph.D. Thesis (unpublished), University of Liverpool.

Wu, Y.T., Fuller, M. and Schmidt, V.A., 1974. Microanalysis of N.R.M. in a granodiorite intrusion. Earth Planet. Sci. Lett., 23: 275-285. 